\title{
Impact Forces and Energy of Flow-like Landslides Against Protection Barriers: a New MPM-validated Empirical Formulation
}

\section{Angela Di Perna}

University of Salerno: Universita degli Studi di Salerno

Sabatino Cuomo ( $\nabla$ scuomo@unisa.it)

Universita degli Studi di Salerno https://orcid.org/0000-0001-8024-0319

Mario Martinelli

Deltares and Technical University of Delft

\section{Research Article}

Keywords: impact mechanisms, mitigation, structure, Material Point Method

Posted Date: January 3rd, 2022

DOI: https://doi.org/10.21203/rs.3.rs-1197305/v1

License: (c) (i) This work is licensed under a Creative Commons Attribution 4.0 International License.

Read Full License 
Impact forces and energy of flow-like landslides against protection barriers: a new MPMvalidated empirical formulation

\author{
Angela Di Perna*, Sabatino Cuomo*, Mario Martinelli^ ${ }^{\wedge \wedge}$
}

* University of Salerno, Italy

$\wedge$ Deltares, Delft, Netherlands

$\wedge \wedge$ Technical University of Delft, Netherlands

\title{
Abstract
}

Full understanding the interaction mechanisms between flow-like landslides and the impacted protection structures is an open issue. In fact, while researchers have used several approaches, from experimental to numerical, it is true that the adequate assessment of the hydromechanical behaviour of the landslide body requires both a multiphase and large deformation approach.

This paper firstly proposes a conceptual framework for a specific type of protection structure, namely a rigid barrier fixed to the base ground. Two different approaches are proposed: i) an advanced hydro-mechanical numerical model based on Material Point Method is tested in simulating the whole complex landslide-structure-interaction mechanism(s), ii) a more simplified empirical model is casted to estimate the impact force and the time evolution of kinetic energy. The calibration and validation of the empirical formulation are pursued, respectively, based on the MPM numerical results, and referring to a large dataset of field evidence for the peak impact pressure. Finally, the performance of the newly proposed empirical method is compared to the methods available in the literature and its advantages are outlined.

Keywords: impact mechanisms, mitigation, structure, Material Point Method

\section{List of abbreviations}

$a_{1}(-) \quad$ coefficient of the power law

$a_{2}(-) \quad$ coefficient of the power law

$\mathbf{a}_{L}\left(\mathrm{~m} / \mathrm{s}^{2}\right) \quad$ liquid acceleration

$\mathbf{a}_{\mathrm{S}}\left(\mathrm{m} / \mathrm{s}^{2}\right) \quad$ solid acceleration

$B(m)$

$b(m)$ greater base of the barrier

b $(k P a)$ smaller base of the barrier

$c^{\prime}(k P a)$

$d(m)$

$\mathbf{D}(k P a)$

$\mathrm{d} p_{L}(k P a)$

$\mathrm{d} \boldsymbol{\sigma}^{\prime}(k P a)$

body force vector

effective cohesion

$E(k P a)$

distance between landslide and barrier

tangent stiffness matrix

excess pore pressure

increment of effective stress

$E_{k, 1}(k J)$

Young modulus of soil

kinetic energy of the landslide 
$F_{1}(k N / m) \quad$ contact force along the base of the flow

$45 \quad F_{2}(k N / m) \quad$ impact force along the side of the barrier

$46 \quad F_{3}(k N / m) \quad$ contact force along the smaller base of the barrier

$47 \quad F_{\text {peak }, \text { dyn }}(\mathrm{kN} / \mathrm{m}) \quad$ dynamic peak impact force

$48 \quad F_{\text {peak,stat }}(\mathrm{kN} / \mathrm{m}) \quad$ static peak impact force

$49 \quad F r(-) \quad$ Froude number

$50 \quad \boldsymbol{f}_{d}(k P a) \quad$ drag force vector

$51 \boldsymbol{g}\left(\mathrm{m} / \mathrm{s}^{2}\right) \quad$ gravity vector

$52 \quad k\left(m^{2}\right) \quad$ intrinsic permeability

$53 \quad k_{\text {sat }}(\mathrm{m} / \mathrm{s}) \quad$ saturated hydraulic conductivity

$54 \quad \mathbf{K}_{\mathrm{L}}(\mathrm{kPa}) \quad$ elastic bulk modulus of the liquid

$55 \quad h(m)$

$56 \quad H(m)$

$57 \quad L S I$

$58 \quad L_{1}(m)$

$59 \quad L_{2}(m)$

60 MPM

$61 \quad m_{1}(\mathrm{~kg})$

$n(-)$

$p_{L}(k P a)$

$t(s)$

flow heigth

barrier heigth

$t_{0}(s)$

Landslide-Structure-Interaction

flow length

length of barrier's lateral side

Material Point Method

$t_{\text {imp }}(s)$

$67 t_{f}(s)$

landslide mass

porosity

liquid pressure

time

initial reference time

$T_{1}(s)$

time related to $L S /$ beginning

$T_{2}(s)$

final time of $L S I$

time related to the peak impact force

$V_{1}\left(m^{3}\right)$

final time of impact phase

$V_{f, H L}\left(m^{3}\right)$

volume of the mixture

$V_{L}\left(m^{3}\right)$

$V_{S}\left(m^{3}\right)$

volume retained by the barrier

$\mathbf{v}_{L}(\mathrm{~m} / \mathrm{s})$

liquid phase volume

solid phase volume

$\mathbf{v}_{\mathbf{S}}(\mathrm{m} / \mathrm{s})$

$\mathbf{v}_{1}(\mathrm{~m} / \mathrm{s})$

$x(m)$

$y(m)$

liquid velocity vector

solid velocity vector

landslide velocity

horizontal Cartesian coordinate

vertical Cartesian coordinate

$\alpha(-)$

$\tau(-)$

$\beta\left({ }^{\circ}\right)$

$\Delta a_{S, \text { contact }}$

dynamic impact coefficient

ratio between $T_{1}$ and $T_{2}$

angle between lateral side and base of the barrier

change in solid phase acceleration induced by the contact formulation

$\Delta a_{L, \text { contact }}$

change in liquid phase acceleration induced by the contact formulation

$\Delta t_{c r}(-)$

critical time step

$85 \delta\left({ }^{\circ}\right)$

$86 \boldsymbol{\varepsilon}(-)$

$87 \kappa(-)$

contact friction angle between flow and barrier

strain vector

static impact coefficient

$88 \mu_{L}(k P a \cdot s)$

$89 v(-)$

liquid dynamic viscosity

$90 \rho_{L}\left(\mathrm{~kg} / \mathrm{m}^{3}\right)$

Poisson's ratio

$91 \rho_{m}\left(\mathrm{~kg} / \mathrm{m}^{3}\right)$

liquid density

$\rho_{m}\left(\mathrm{~kg} / \mathrm{m}^{3}\right)$

density of the mixture

solid density

$\sigma(k P a)$

total stress tensor of the mixture

$94 \dot{\boldsymbol{\sigma}}(\mathrm{kPa} / \mathrm{s})$

Jaumann stress rate matrix

$\sigma_{n}(k P a)$

normal stress

$\varphi^{\prime}\left({ }^{\circ}\right)$

internal friction angle

$97 \quad \psi\left({ }^{\circ}\right)$

dilatancy angle 
The interaction of flow-like landslides with rigid walls, obstacles, protection structures and, more recently, single building or cluster of buildings have been investigated by a variety of numerical tools. The massive use of numerical methods is related to the inner complexity of Landslide-StructureInteraction (LSI) mechanisms, which are related to: i) the hydro-mechanical features of the impacting flow, ii) the geometry of the structure, and iii) initial and boundary conditions for the specific LSI problem. Applications of Discrete Element Method (DEM) has been reported by Leonardi et al. (2016), Calvetti et al. (2017) and Shen et al. (2018). However, a number of continuum mechanics models based on Eulerian methods (Moriguchi et al. 2009), Lagrangian particle-based methods such as Smoothed-Particle Hydrodynamics (SPH), Particle Finite Element Method (PFEM), Finite Element Method with Lagrangian integration points (FEMLIP), Material Point Method (MPM), (Idelsohn et al. 2006; Bui and Fukagawa 2013; Cuomo et al. 2013; Ceccato et al., 2018) have been also applied. Some coupled Eulerian-Lagrangian methods (Qiu et al. 2011; Jeong et al. 2019) have been also used. Recently the solid-fluid hydro-mechanical coupling and the role of the interstitial fluid in the LSI mechanisms have been considered. For instance, the impact behaviour of saturated flows against rigid barriers was simulated through MPM analyses, with a satisfactory correspondence with the experimental centrifuge test results (Cuomo et al., 2021). Most of these approaches are very recent, and still need comprehensive validation combined with more efforts to reduce the computational cost, which is very high once realistic simulations are pursued.

A more traditional approach is based on: i) direct observation of impact of flow-like landslides against barriers, and ii) correlation of the achieved measurements.

The measurements available in the literature have been mostly obtained in reduced-scale flume tests (Hübl et al., 2009; Armanini et al., 2011; Canelli et al., 2012; Ashwood and Hungr, 2016; Vagnon and Segalini, 2016), or in some cases in full-scale flume experiments (De Natale et al., 1999; Bugnion et al., 2012). For instance, the interpretation of a wide set of reduced-scale laboratory experiments on dry granular flows allowed Faug (2015) to propose a so-called phase-diagram based on (i) Froude number (Fr) and (ii) obstacle height relative to the flow depth (H/h). The diagram comprises four LSI mechanisms: a) Dead zone (i.e. gradual accumulation of material behind the obstacle): this is the case of relatively slow flows $(\mathrm{Fr}<\approx 1)$ impacting relatively small obstacles $(\mathrm{H} / \mathrm{h} \approx 1)$; b) Airborne jet (forming downstream of the obstacle): this stands for rapid flow (Fr $\gg 1)$ and obstacle height low; c) Standing jumps (propagating downstream of the obstacle with steadystate conditions): for rapid flow $(F r \gg 1)$; d) Bores (a granular jump hits the obstacle and propagates upstream of it): in the case of a rapid flow $(F r \gg 1)$ hitting a wall spanning the entire width of the flow $(H / h \gg 1)$ with unsteady conditions. However, the interstitial water may largely contribute to change/regulate the landslide-structure interaction mechanism(s), and new insights will be proposed in this paper. 
136

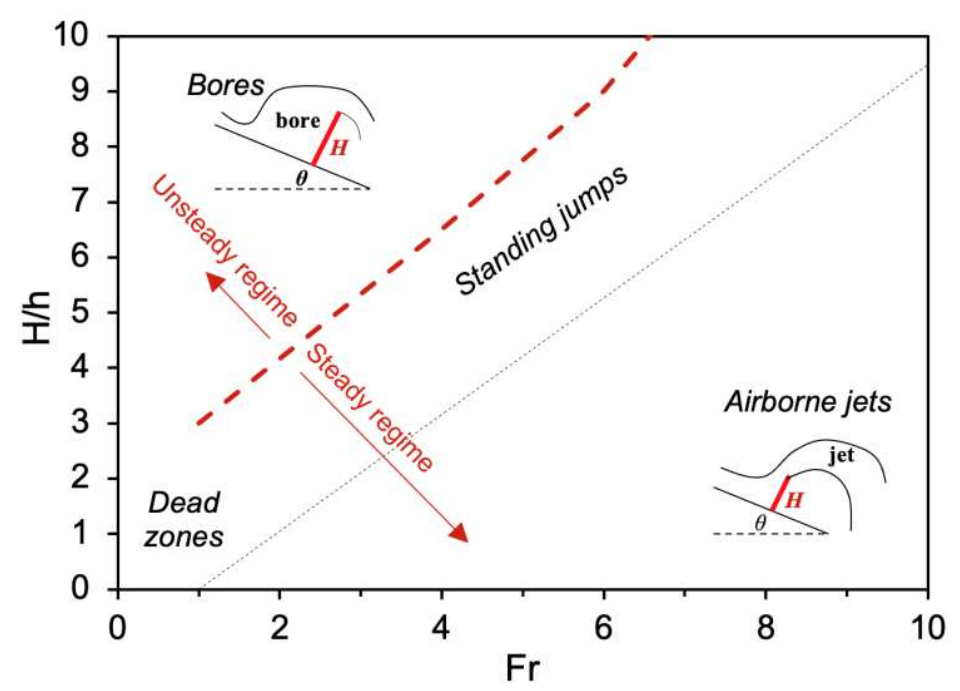

Figure 1. Interaction diagram for a flow impacting an obstacle (adapted from Faug, 2015)

In general, the reduced-scale laboratory tests have been extensively used to derive and validate the empirical formulations most commonly used to assess the peak impact pressure in the design of protection measures against landslide (Schield et al., 2013; Scotton and Deganutti, 1997; Arattano and Franzi 2003; Hübl et al., 2009; Proske et al., 2011; Bugnion et al. 2012; Canelli et al. 2012; He et al. 2016; Song et al., 2021). The existing empirical methods can be classified into three groups: (i) hydro-static methods, which require only flow density and thickness for evaluating the maximum impact pressure; (ii) hydro-dynamic methods, based on flow density and the square velocity of the flow; (iii) mixed methods, that accounts for both the static and the dynamic components of the flow. The weak point is that the empirical formulations greatly depend on empirical coefficients which are difficult to estimate in the practical applications due to their wide range of variation. Common to those approaches are the following assumptions: (i) the impact load is assumed to be totally transferred to the structure without any dissipation during the impact, and (ii) the size, stiffness and inertial resistance of the artificial barrier are not considered (Vagnon and Segalini, 2016). These assumptions generally lead to safe assessment of the peak impact force but with large overestimation of the barrier design. Hence, enhancements will be proposed in this paper on both these topics.

The present work investigates the impact mechanisms of flow-like landslides against artificial barriers in full-scale realistic scenarios. A Conceptual Model of Landslide-Structure-Interaction (LSI) is firstly proposed. Then, two methods are evaluated in this paper: (i) a Material Point Method approach is used to analyse the hydro-mechanical interaction of saturated flows with different types of barriers, (ii) an empirical method is casted to evaluate the peak impact horizontal force and reduction in kinetic energy of the flow. The new empirical formulation is calibrated with a set of numerical MPM results and validated with a large dataset of field evidence of impact problems. Then, 
the novel empirical formulation is compared with those from the literature and its potential and limitations are discussed.

\section{A conceptual framework for Landslide-Structure-Interaction (LSI)}

The proposed conceptual model for Landslide-Structure-Interaction (LSI) considers a flow-like landslide mass that impacts against a barrier fixed to the base ground (Fig. 2). The landslide body has the following features: unitary width, length $L_{1}$, depth $h$, density of the mixture $\rho_{m}$, initial uniform velocity $v_{1,0}$, pore-water pressure $p_{L}$ and friction angle along the base ground equal to $\tan \varphi_{b}$. The barrier is typically represented by a reinforced concrete vertical wall or by an embankment with a steep inclined face at the impact side. For the sake of generality, here below we consider that the barrier is trapezoidal shaped, with the geometric characteristics being as follows: greater base $B$, smaller base $b$, height $H$, inclination of the impacted side $\beta$.

The $L S I$ problem is described through the following timelines: initial configuration $\left(t_{0}\right)$, landslide propagation $\left(t_{0}<t<t_{\text {imp }}\right)$, impact of the landslide front $\left(t_{\text {imp }}\right)$, time of the peak impact force $\left(T_{1}\right)$, start of the inertial stage $\left(T_{2}\right)$, end of $L S I\left(t_{f}\right)$. Before the landslide reaches the barrier $\left(t_{0}<t<t_{\text {imp }}\right)$, i.e., during the propagation stage, the $L S I$ problem is governed by the basal frictional force $F_{1}$ (Eq. 1 ), which acts along the bottom of the flow $\left(L_{1}\right)$ and controls the reduction in flow velocity, resulting in a decrease of the impact forces. Once the flow starts to interact with the barrier $\left(t_{i m p}<t<T_{2}\right)$, additional stresses (mostly orthogonal to the impacted surface, hence horizontal in many applications) are produced at the impacted side of the barrier. Many studies (e.g., Cui et al., 2015; Song et al. 2017) demonstrated that the total impact force-time history can be simplified as a triangular force impulse, usually with a rise time $\left(T_{1}\right)$ much shorter than the decay time $\left(T_{2}-T_{1}\right)$.

According to the Newton's Third law of motion, the mutual impact forces $\left(F_{2}\right)$ between the landslide and the barrier are equal and opposite. Such mutual stress makes: (i) the flow to decelerate and (ii) the barrier to slip along the base and to deform itself, as shown in Fig. 2. The evaluation of the impact forces applied on the inclined side of the barrier $\left(L_{2}\right)$ is fundamental to design the structural characteristics of the barrier (Eq. 2). It is worth noting that the flow may overtop the barrier during the impact, generating an additional force $F_{3}$ on the structure (Eq. 3), mainly dependent on the flow-barrier frictional contact $(\tan \delta)$.

Once the action $F_{1}, F_{2}$ and $F_{3}$ are known, the stability of the barrier can be determined through the evaluation of the constraint reactions by solving the equilibrium of forces and moments. In this way, it is possible to assess the ultimate strength to which the foundation systems must be designed, or to understand what resistance must be mobilized at the base, so that the barrier does not move. The latter option can be put into practice by placing a layer of soil material suitable to give an assigned frictional resistance to the base of the barrier. 


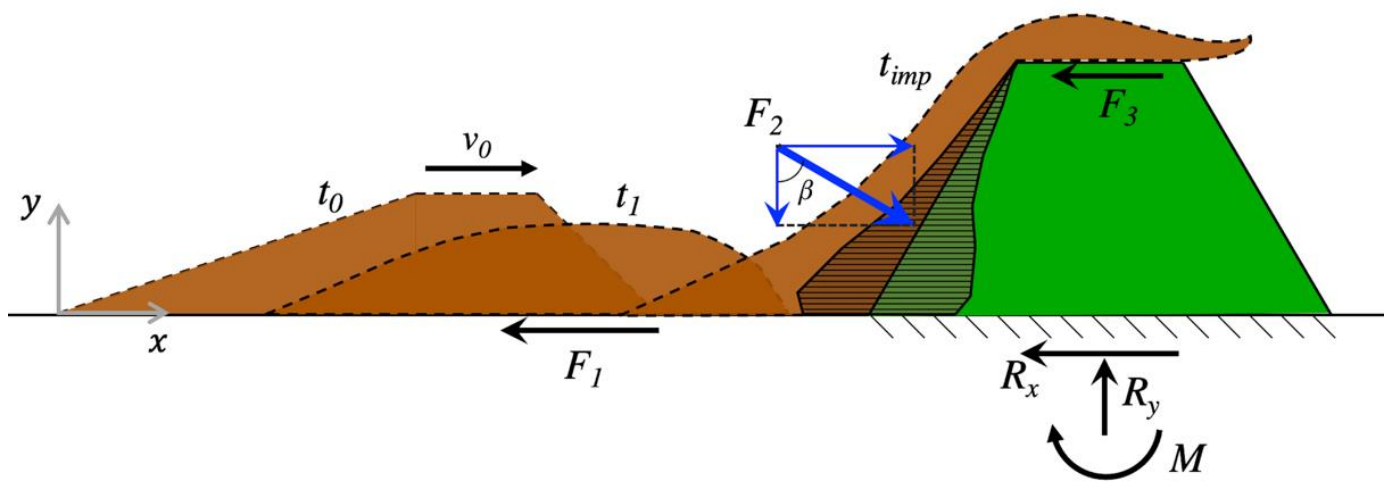

\subsection{Governing equations and input data}

It is quite difficult to propose a standard landslide configuration as initial condition since it must represent the shape of the flow in a certain moment of its propagation stage. As known, this configuration strongly depends on the flow-path topography and on the geomorphological conditions that can vary from site to site. However, many studies have demonstrated that the front is often higher than the rear portion due to friction with the ground topography (Iverson, 1997; Thouret et al., 2020). For this reason, the chosen initial configuration of the landslide is characterized by a $45^{\circ}$ inclined front and a tail of length equal to three times the flow height. To consider different flow volumes, an $i$ number of squares have been placed between the head and tail portions. Given this shape, the landslide as the same volume of an equivalent rectangular with the same height $h$ and a length $L_{m}=(2+i) \cdot h$, and unitary width (Fig. 3).

The flow and barrier are modelled through the single-point MPM formulation, respectively with 2phase and 1-phase, both described in the Appendix 1. For the barrier it is assumed: non-porous material, the base fixed to the ground and rigid behaviour. This last hypothesis relates to the construction mode typically used for such barriers (Cuomo et al., 2019). To schematize the problem 
in a realistic way, the build-up of excess pore pressure in the flow material during the impact is considered as well as the hydro-mechanical coupled behaviour and the yielding of the flow material.

The influence of different impact scenarios on the dynamics and kinematics in a LS/ problem have been investigated. The geometric features of both the landslide and the barrier are summarized in Table 1. It is worth noting that the case of an infinite wall is that considered in the literature empirical models. The mechanical properties of the saturated flow mass and the friction angle at the contact with the barrier are reported in Table 2. The numerical MPM analyses evidently allow the simultaneous simulation of flow propagation and flow-structure interaction. The flow is a saturated mixture with hydrostatic distribution of initial pore-water pressure. Although simplified, the landslide scheme resembles its main characteristics such as velocity, impact height, non-zero interstitial pressures and elasto-plastic behavior. The computational unstructured mesh is made of 20,515 triangular 3-noded elements with dimensions ranging from 0.20 to $1.00 \mathrm{~m}$. The landslide is assumed as approaching the barrier with a fixed geometric configuration and constant velocity, until LSI starts.

The phase diagram proposed by Faug (2015) for granular flow-structure interaction is here used here to predict the type of impact mechanism expected for each scenario (Table 3). The Froude number is here calculated as $v_{0} \operatorname{sen} \beta / \sqrt{g h}$, considering the inclination $\beta$ of the impacted side of the barrier. For practical applications, this could be useful to preliminary assess the potential efficiency of the barrier in intercepting the propagation of the flow under different impact conditions.

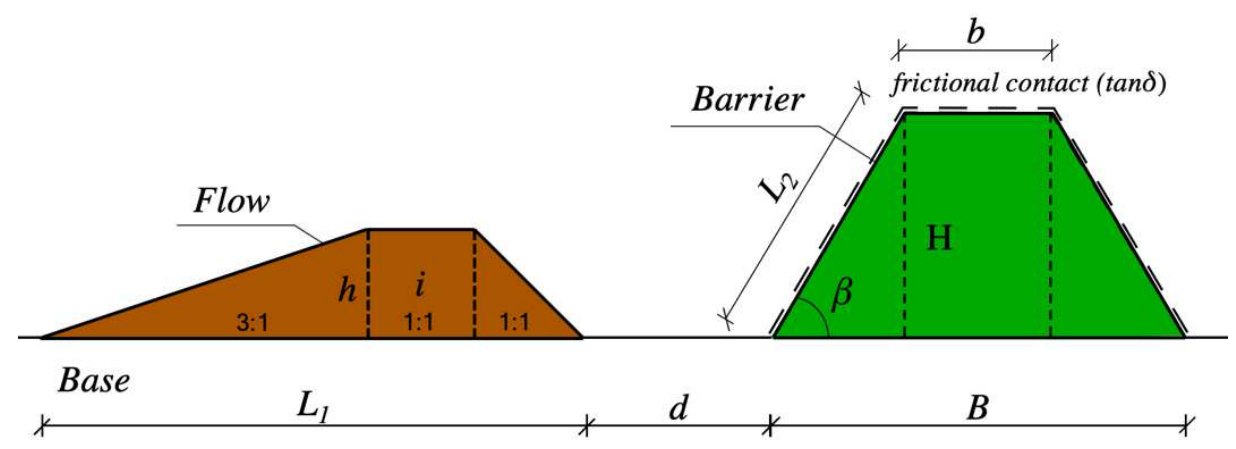

Figure 3. Geometric schematization of the problem in the numerical model

Table 1. Geometric features for different scenarios

\begin{tabular}{ccccccccccccc}
\hline ID & $\begin{array}{c}L_{1} \\
(m)\end{array}$ & $\begin{array}{c}L_{m} \\
(m)\end{array}$ & $\begin{array}{c}i \\
(-)\end{array}$ & $\begin{array}{c}h \\
(m)\end{array}$ & $\begin{array}{c}V_{1} \\
\left(\mathrm{~m}^{3} / m\right)\end{array}$ & $\begin{array}{c}v_{0,1} \\
(\mathrm{~m} / \mathrm{s})\end{array}$ & $\begin{array}{c}\beta \\
\left({ }^{\circ}\right)\end{array}$ & $\begin{array}{c}d \\
(m)\end{array}$ & $\begin{array}{c}L_{2} \\
(\mathrm{~m})\end{array}$ & $\begin{array}{c}B \\
(m)\end{array}$ & $\begin{array}{c}b \\
(m)\end{array}$ & $\begin{array}{c}H \\
(m)\end{array}$ \\
\hline 1 & 21.00 & 15.00 & 3 & 3.00 & 45.00 & 10 & 60 & 3.00 & 6.95 & 11.00 & 4.00 & 6.00 \\
\hline 2 & 21.00 & 15.00 & 3 & 3.00 & 45.00 & 20 & 60 & 3.00 & 6.95 & 11.00 & 4.00 & 6.00 \\
\hline 3 & 21.00 & 15.00 & 3 & 3.00 & 45.00 & 10 & 90 & 3.00 & $\infty$ & - & - & $\infty$ \\
\hline 4 & 47.00 & 45.00 & 43 & 1.00 & 45.00 & 10 & 60 & 3.00 & 6.95 & 11.00 & 4.00 & 6.00 \\
\hline
\end{tabular}


Table 2. Mechanical properties

\begin{tabular}{ccccccccccc|cc}
\hline \multicolumn{10}{c|}{ Flow-like landslide } & \multicolumn{3}{c}{ Barrier } \\
\hline $\begin{array}{c}\rho_{m} \\
\left(\mathrm{~kg} / \mathrm{m}^{3}\right)\end{array}$ & $\begin{array}{c}\rho_{s} \\
\left.\mathrm{~kg} / \mathrm{m}^{3}\right)\end{array}$ & $\begin{array}{c}n \\
(-)\end{array}$ & $\begin{array}{c}K_{0} \\
(-)\end{array}$ & $\begin{array}{c}\varphi^{\prime} \\
\left(^{\circ}\right.\end{array}$ & $\begin{array}{c}c^{\prime} \\
(\mathrm{kPa})\end{array}$ & $\begin{array}{c}E^{\prime} \\
(\mathrm{MPa})\end{array}$ & $\begin{array}{c}v \\
(-)\end{array}$ & $\begin{array}{c}k_{\text {sat }} \\
(\mathrm{m} / \mathrm{s})\end{array}$ & $\begin{array}{c}\mu_{L} \\
(P a s)\end{array}$ & $\begin{array}{c}K_{L} \\
(\mathrm{MPa})\end{array}$ & $\begin{array}{c}\rho \\
\left(\mathrm{kg} / \mathrm{m}^{3}\right)\end{array}$ & $\begin{array}{c}\tan (\delta) \\
(-)\end{array}$ \\
\hline 1800 & 1300 & 0.5 & 0.66 & 20 & 0 & 2 & 0.25 & $10^{-4}$ & $10^{-3}$ & 30 & 2000 & 0.29 \\
\hline
\end{tabular}

Table 3. Expected impact mechanism

\begin{tabular}{cccc}
\hline ID & $\begin{array}{c}F r \\
(-)\end{array}$ & $\begin{array}{c}H / h \\
(-)\end{array}$ & Impact mechanism* \\
\hline 1 & 1.59 & 2.0 & Standing jump \\
\hline 2 & 3.19 & 2.0 & Airborne jets \\
\hline 3 & 1.84 & $\infty$ & Bores \\
\hline 4 & 2.76 & 6 & Bores \\
\hline * from the application of the diagram proposed by Faug (2015)
\end{tabular}

\subsection{Numerical MPM results}

Selected results are shown in Figures 4-5, where the spatial distribution of pore-water pressure is illustrated at different time instants of the propagation stage for all scenarios of Table 1. During the impact, the initial liquid pressure $(<30 \mathrm{kPa})$ changes over time, with the maximum value in the first instants of the impact process $(t=1 \mathrm{~s})$ and later diminishing down to nil in some cases. However, the maximum value of pore water pressure $\left(p_{L, \max }\right)$ is dependent on the type of barrier. In fact, comparing an infinite wall (Fig. 4a) with a fixed artificial barrier (Fig. 4b), it follows that $p_{L, \max }$ is higher in the first case, where the overtopping is not allowed and the impacted area of the barrier is larger than for the artificial barrier $(t=1 \mathrm{~s})$. At $t=2 \mathrm{~s}$, the flow overtops the wall (Fig. 4a) or goes beyond the barrier forming a prolonged jet (Fig. 4b). Liquid pressure is decreasing, indicating that we are in the decay zone of the impact force diagram. Subsequently $(4 s<t<6 s)$, the flow loses more and more energy and falls downwards (similarly, in both cases). The expected impact mechanism, as assessed from the use of the diagram by Faug (2015), is confirmed in both the cases. For the infinite vertical wall, the impact mechanism resembles the bores regime since a granular jump (named "bore") is formed which heads upstream of the wall. For the embankment barrier, the impact mechanism is the standing jump, which is similar to the bores regime but here a part of the incoming flow is able to overtop the barrier, forming a jet with very low energy.

Different flows are also considered to investigate other impact mechanisms (Fig. 5). High flow velocities induce large values of $p_{L, \max }$, which reaches $260 \mathrm{kPa}$ (Fig. 5a). In this case, the expected impact mechanism is an airborne jet (Table 3 ) and it is confirmed very well from the numerical 
273 simulation. A very prolonged jet with high energy is formed after the impact, thus the amount of 274 material that is retained by the barrier is much smaller than the standing jump case. Completely 275 different is the case of a shallow flow (Fig. 5b), where the flow hits the obstacle and propagates upstream in unsteady conditions (bores regime). The flow has a very low reduction in kinetic energy, however the flow does not overtop the barrier.

Overall, the cases 1, 2 and 4 suggest a clear link between pore-water pressures at impact and the amount of overtopping flow mass, where larger pore-water pressures facilitate the overtopping of the barrier. This finding is also confirmed by previous experimental research (Song et al., 2017; Zhou et al., 2018).

Fig. 6 shows the landslide-structure interaction from both a dynamic and kinematic point of view. The peak of the horizontal and vertical components of the impact force $\left(F_{2, x}\right.$ and $F_{2, y}$, respectively in Fig. 6a) are quite different in all cases. In particular, the forces have a clear peak for case 1, 2 and 3 , with higher values as the velocity increases and as the impacted side gets steeper. Conversely, case 4 does not show any distinct peak, where the impact forces are very limited.

The temporal variation of the forces $F_{3}$ and $F_{4}$ (defined in Fig. 2) are also illustrated in Fig. 6b. The frictional force above the barrier $\left(F_{3}\right)$ is caused by the overtopping volume. In fact, the highest value is in case 2 , where the retained volume is the smallest. This force can also have a negative sign when the flow goes upstream, instead of flowing beyond the barrier. However, for what concerns the global momentum balance of the barrier, the contribution of $F_{3}$ is negligible compared to the frictional force at the base of the barrier $F_{4}$.

For the sake of simplicity, the flow basal frictional force $F_{1}$ is assumed equal to zero in all cases, 294 by means of a smooth contact.

295 The kinetic energy of the incoming flow $\left(E_{k 1}\right)$ is plotted in Fig. 6. In order to make a more 296 comprehensive comparison, the curves are normalized by the initial kinetic energy of the flow $\left(E_{k 1,0}\right)$. The curves of cases 1,2 and 3 show a sudden reduction, reaching the minimum value at approximately $t \cong 2 \mathrm{~s}$ and, after that, the energy increases again as the formed jet takes the downward direction. This means that, during the flow, the kinetic energy is transformed to potential energy. In particular, for $t>2 s$ all the trends are very different, since the curves represent the kinetic energy of the overcoming jet (especially for cases 1 and 2) combined with the energy of the reflecting flow (especially for case 3). The behavior of case 4 is completely different: it is characterized by a slower and constant reduction of the energy as the impact mechanism does not induce the formation of any jet. 


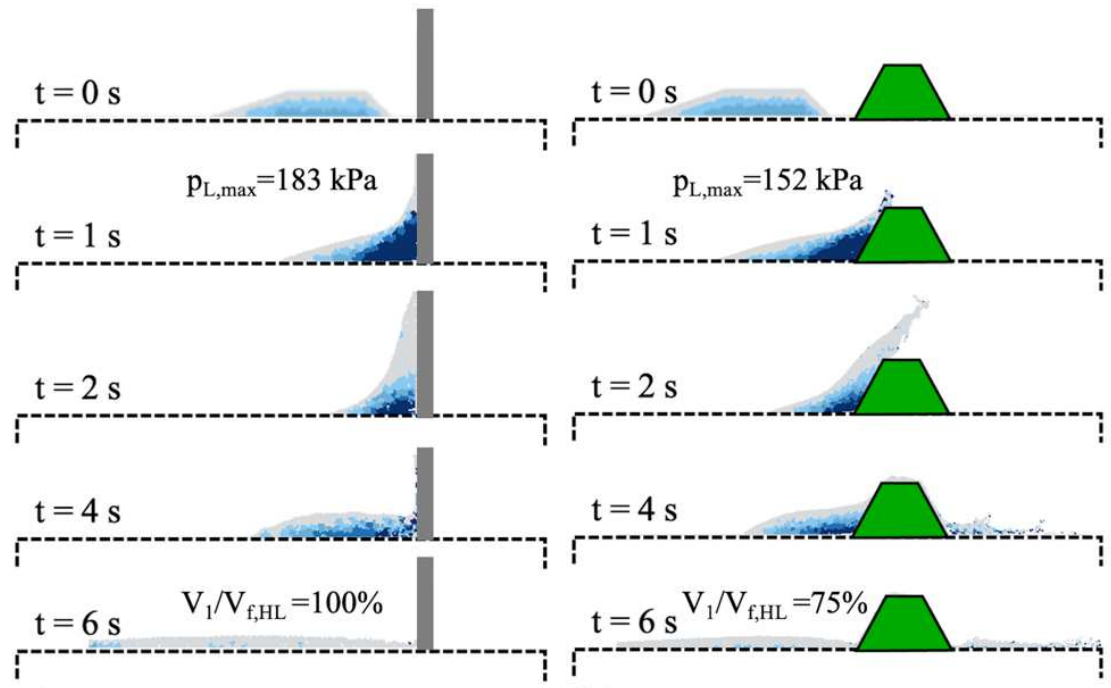

a)

b)
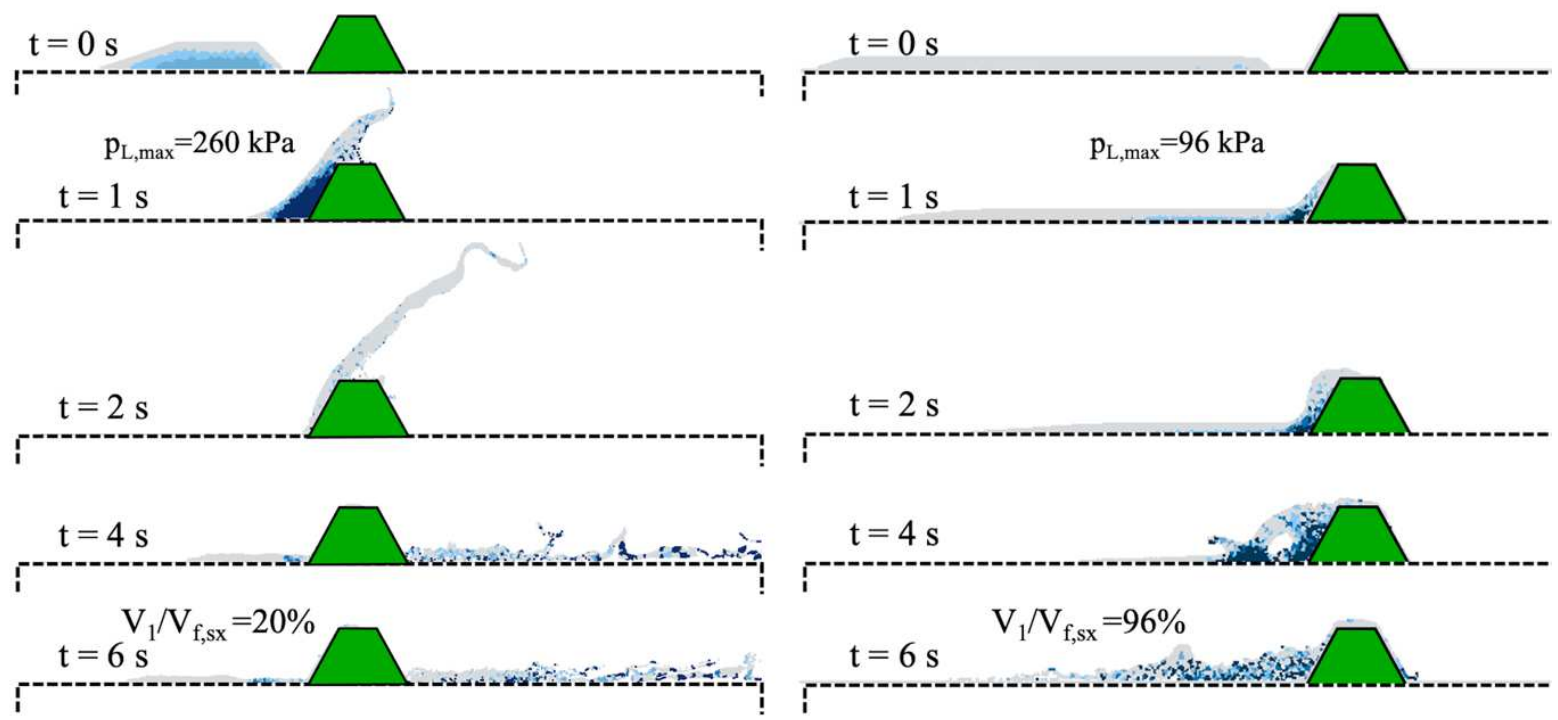

a)

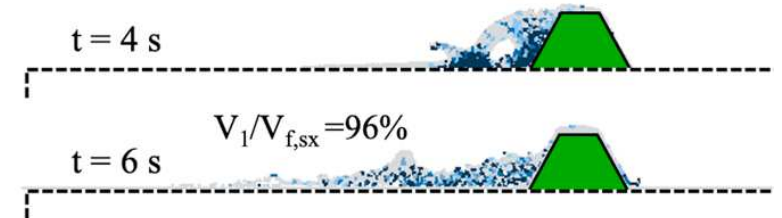

b)

Figure 5. Pore-water pressure distribution for different flows:

(a) $v_{0}=20 \mathrm{~m} / \mathrm{s}$ (case 2); (b) $H / h=6$ (case 4) 

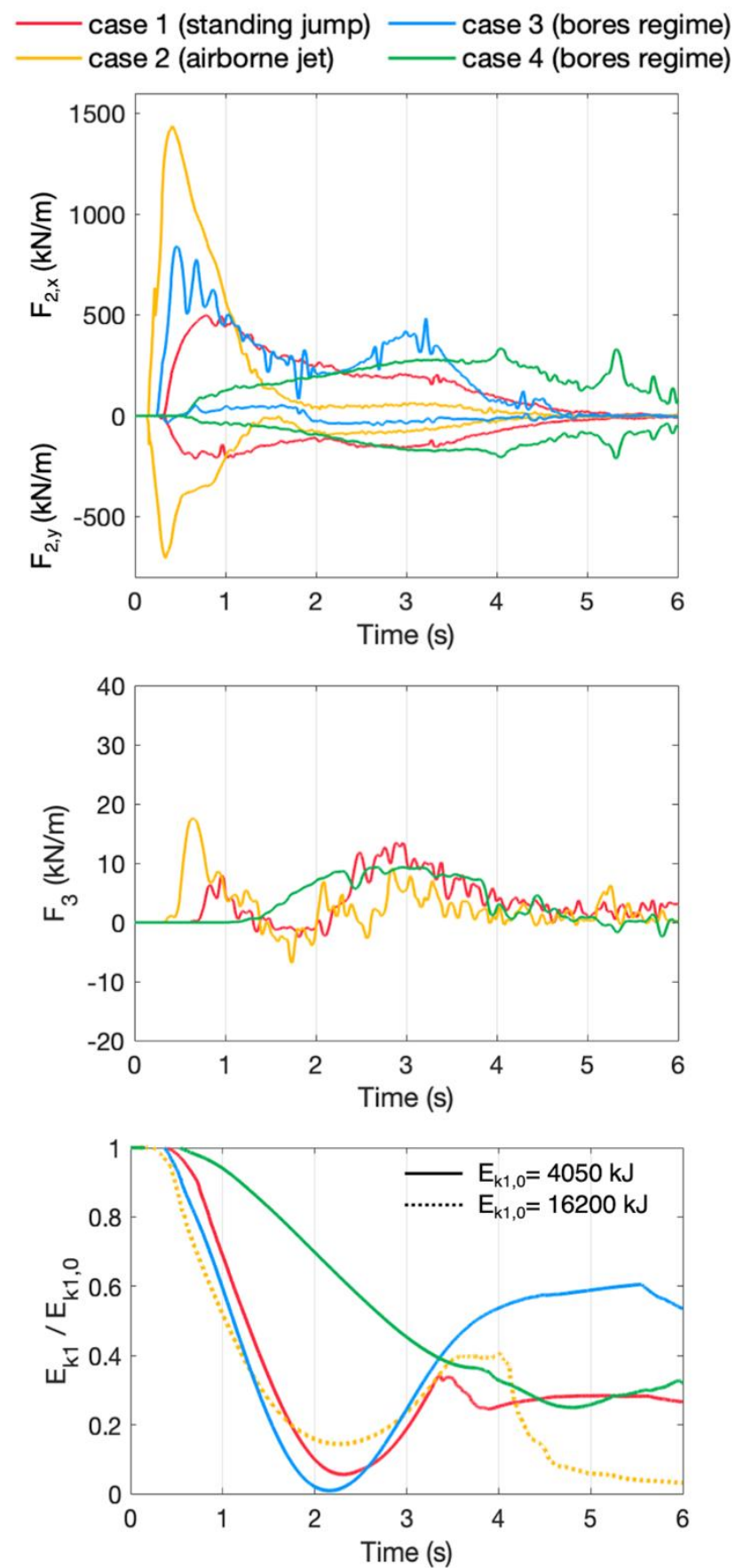

\subsection{Formulation}

Figure 6. Impact forces and kinetic energy of the flow different scenarios

In a simplified approach, the landslide mass is here schematized as an equivalent solid-like body, rectangular, with mass $m_{1}$, length $L_{1}$, depth $h$, unitary width, density $\rho_{m}$, initial velocity $v_{1,0}$ and it is 
supposed to be completely stopped by the barrier (i.e., $v_{1}\left(T_{2}\right)=0$ ). The latter is assumed as fixed to the base ground and indefinitely high, thus all the landslide volume is supposed to be retained by 321 the barrier.

Based on the previous studies (Hungr et al., 1984; Scotton and Deganutti, 1997; Kwan, 2012), the peak lateral force $F_{\text {peak }}$ (Eq. 4) exerted by the flow on the obstacle is calculated by the sum of a dynamic component $F_{\text {peak,dyn }}$ (Fig. 7a) and a height-dependent static component $F_{\text {peak,stat }}$ (Fig. 7b), as reported in Eqs. 5-6, respectively.

$F_{\text {peak }, \text { dyn }}=\alpha \rho_{m} v_{1,0}^{2} h$

a)
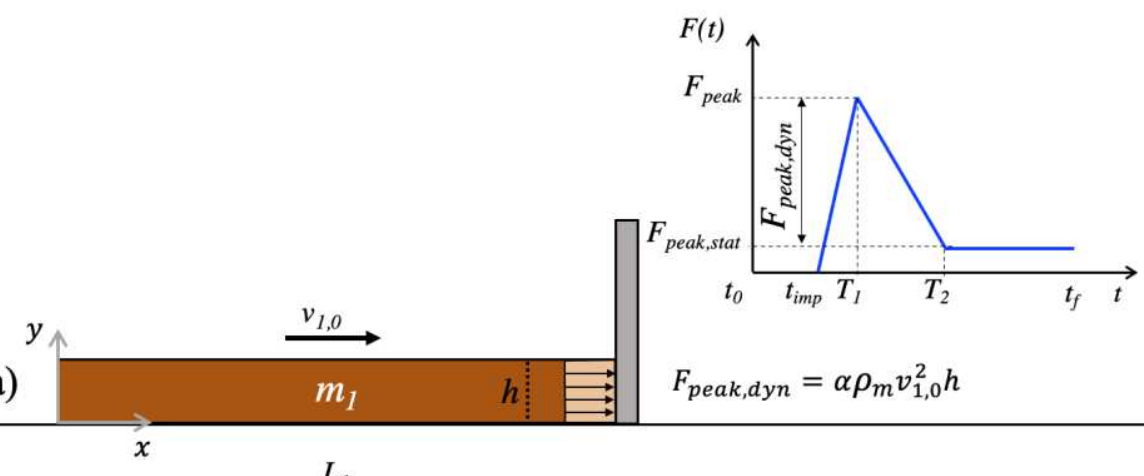

$F_{\text {peak }, d y n}=\alpha \rho_{m} v_{1,0}^{2} h$

Figure 7. Schematic of the impact problem in the proposed empirical model

The empirical coefficient $\alpha$ has a wide range of values, ranging from 0.4 to 12 (Vagnon et al., 2020), while the empirical static coefficient $\kappa$ ranges from 9 to 11 as reported by Armanini (1997) or in the range 3-30 as observed by Scheidl et al. (2013) for $F r<3$. This static coefficient is suggested to be assumed equal to 1 ( $\mathrm{Ng}$ et al., 2021) for saturated flows that are fluidized due to the increasing pore pressure inside the landslide. In this paper, the value of $\alpha$ is calibrated based on the MPM simulation of a selected set of realistic cases.

The landslide kinetic energy during the impact process is derived from its velocity variation over 
time until the impact process finishes $\left(T_{2}\right)$. The impulse theorem (Eq. 7), where the impulse of the impact force is equal to the variation of linear momentum, the link between the impact pressure and velocity variation is obtained (Eq. 8). It is worth noting that the size of the impacted area (equal to $h$ in a 2D simplification) is eliminated, being on both sides of the equation. It is implicitly assumed that the dynamic pressure is constant with the depth thus independent of $h$ (Fig. 7a).

Since the time-trend of the impact pressure is a piecewise function, the equations system reads as in Eq. 9. This means that Eq. 8 is transformed into Eq. 10.

$I=\int_{0}^{T_{2}} F(t) d t=\int_{v_{1,0}}^{0} m_{1} d v$

$\int_{0}^{T_{2}} p(t) d t=\int_{v_{1,0}}^{0} m_{1} d v$

$p(t)=\left\{\begin{array}{lr}\frac{p_{\text {peak }}}{T_{1}} t & 0<t<T_{1} \\ p_{\text {peak }}-\frac{p_{\text {peak,dyn }}}{\left(T_{2}-T_{1}\right)}\left(t-T_{1}\right) & T_{1}<t<T_{2}\end{array}\right.$

$\int_{0}^{T_{1}} p(t) d t+\int_{T_{1}}^{T_{2}} p(t) d t=\int_{v_{1,0}}^{0} m_{1} d v$

The reduction in landslide velocity is obtained from Eq. 11, by solving the integrals in Eq. 10 and replacing the term $p(t)$ with Eq. 9. Thus, the flow velocity over time (Eq. 12) and the corresponding kinetic energy (Eq. 13) can be computed.

$v_{1}(t)=v_{1,0}-\Delta v_{1}(t)$

$\Delta v_{1}(t)=\left\{\begin{aligned} \frac{1}{m_{1}} \cdot \frac{p_{\text {peak }}}{T_{1}}\left(\frac{t^{2}}{2}\right) \\ \frac{1}{m_{1}}\left[p_{\text {peak }}(t)-\frac{p_{\text {peak,dyn }}}{\left(T_{2}-T_{1}\right)}\left(\frac{t^{2}}{2}\right)\right]\end{aligned}\right.$

$$
\begin{aligned}
& 0<t<T_{1} \\
& T_{1}<t<T_{2}
\end{aligned}
$$

$E_{k, 1}(t)=\frac{1}{2} m_{1} v_{1}^{2}(t)$

The impact period $T_{2}$ is obtained by using the impulse theorem, since the integral over time of the impact force (i.e., the impact impulse) is equal to the variation of linear momentum of the landslide (Eq. 14). The impulse of the impact force can be rewritten in terms of impact pressure, and its formulation is reported in Eq. 15. Once known $T_{2}$ through Eq. 16, $T_{1}$ can be achieved in Eq. 17 by fixing the ratio $\tau=T_{1} / T_{2}$ (for example from experimental evidence). The description of the impact 
dynamics is complete.

Summing up, the model primary unknown is $T_{2}$, while the quantities $\alpha, \kappa$ and $\tau$, must be calibrated/assessed.

$\int_{0}^{T_{2}} F(t) d t=m_{1} v_{1,0}$

$\int_{0}^{T_{2}} F(t) d t=\int_{0}^{T_{2}} p(t) h d t=\frac{1}{2}\left(p_{\text {peak }}+p_{\text {peak }, \text { stat }}-\tau p_{\text {peak }, \text { stat }}\right) h T_{2}$

$T_{2}=\frac{2 m_{1} v_{1,0}}{\left(p_{\text {peak }}+p_{\text {peak }, \text { stat }}-\tau p_{\text {peak,stat }}\right) h}$

$T_{1}=\tau T_{2}$

Some examples are shown in Fig. 8 to highlight the effect of $\alpha, \kappa$ and $\tau$ on impact force and kinetic energy trend over time. The input quantities of the model are: $L_{1}=15 \mathrm{~m} ; h=3 \mathrm{~m} ; \rho_{m}=$ $1800 \mathrm{~kg} / \mathrm{m}^{3} ; v_{1,0}=10 \mathrm{~m} / \mathrm{s}$. High values of $\alpha$ result in large peak forces, short impact time $T_{2}$ and rapid decrease of the kinetic energy of the flow. This means that $\alpha$ can be interpreted as a measure of system deformability, since the decreasing of $T_{2}$ with $\alpha$ means that the system is more stiff.

The empirical coefficient $\kappa$ has similar behaviour compared to $\alpha$, since high values of $\kappa$ result in large peak forces and short time $T_{2}$. However, the coefficient $\kappa$ has a minor influence on the system response compared to the coefficient $\alpha$ (as evident in Fig. 8); for this reason, the static component of the impact force will be disregarded in this study and only the coefficient $\alpha$ will be used for the assessment of the impact scenario.

Finally, the ratio $\tau$ governs the occurrence of the peak time, and thus the shape of the impact force trend. In terms of flow kinetic energy dissipation, the higher the ratio $\tau$, the steeper the dissipation trend up to $T_{1}$ and the slower the energy reduction between $T_{1}$ and $T_{2}$. In a sense, the parameter $\tau$ can be interpreted as a measure of the impulsiveness of the impact loading. 

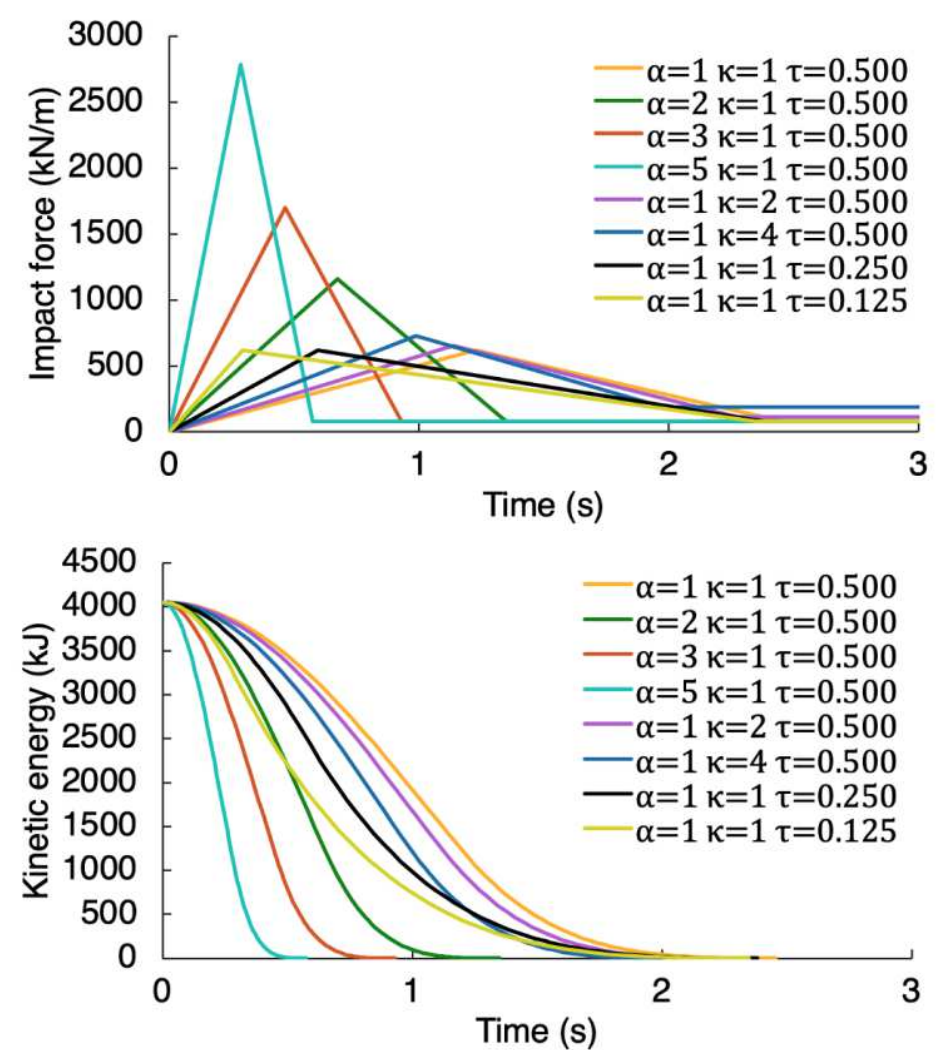

\subsection{Calibration}

The calibration of the empirical model principally focuses on the evaluation of the empirical coefficients $\alpha$ and $\tau$.

The parameter $\tau$ is obtained by imposing the equivalence between $T_{1}$ calculated from Eq. 17, and $\mathrm{T}_{1}$ obtained from the MPM simulations.

The coefficient $\alpha$ relates to relevant features of the flow such as the grain size distribution, the barrier type and the flow-structure interaction mechanism such as the formation of vertical jet-like wave at the impact (Canelli et al., 2012). As reported in the literature, this parameter can vary in a wide range (between 0.4 and 12), often leading to an excessive overestimation of the design impact load. However, many authors (Hubl et al., 2009; Proske et al., 2011; Scheidl et al., 2013; Cui et al., 416 2015; Vagnon, 2020) developed a power law relationship between the coefficient $\alpha$ and the Froude 417 number $(\mathrm{Fr})$, as reported in Eq. 18.

The evaluation of the coefficients $a_{1}$ and $a_{2}$ requires at least two numerical simulations with different Froude number. Apart from cases 1,2 and 3 of Table 1 (case 4 is neglected due to the 
423 impossibility of identifying a unique peak value), other data-sets are used for the calibration of the 424 model (as reported in Table 4), spanning over different values of soil porosity $n$, flow thickness $h$, 425 flow volume $V_{1}$, initial velocity $v_{1,0}$ and the inclination $\beta$. The best fit values are $a_{1}=1.781$ and $a_{2}=$ $426-0.515$ (Fig. 9). The results show a good fitting with the $\alpha-F r$ curve for all the impact scenarios, 427 and it is relevant that also the trend over time of the impact force is reproduced quite faithfully (Fig. 428 9). It entails that the peak impact pressure can be consistently obtained from the following equation: 429

$$
p_{\text {peak }}=1.781 \mathrm{Fr}^{-0.515} \rho_{m} v_{1,0}^{2}
$$

Besides achieving a good correspondence with the impact forces, the trend of flow kinetic energy 433 was computed (Eq. 13) for the impact scenarios, giving for instance better agreement for the case 1 434 than the case 2. In the latter case, this is explained by the fact that high energy of the flow produces 435 a more elongated jet, which cannot be reproduced by a simplified empirical method. The flow kinetic 436 energy computed via empirical method is always lower than that computed through MPM (apart from 437 Set III). This is mostly linked to the simplifying hypothesis of neglecting the static component of the 438 impact force. However, it is a safe approximation, to be considered acceptable in the practice. 


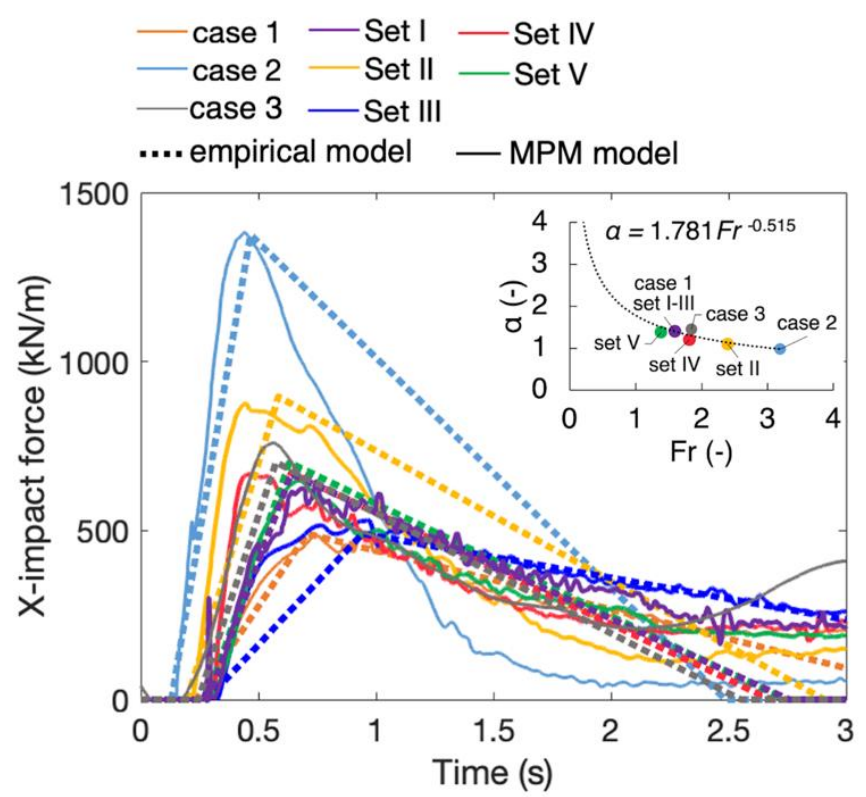

439

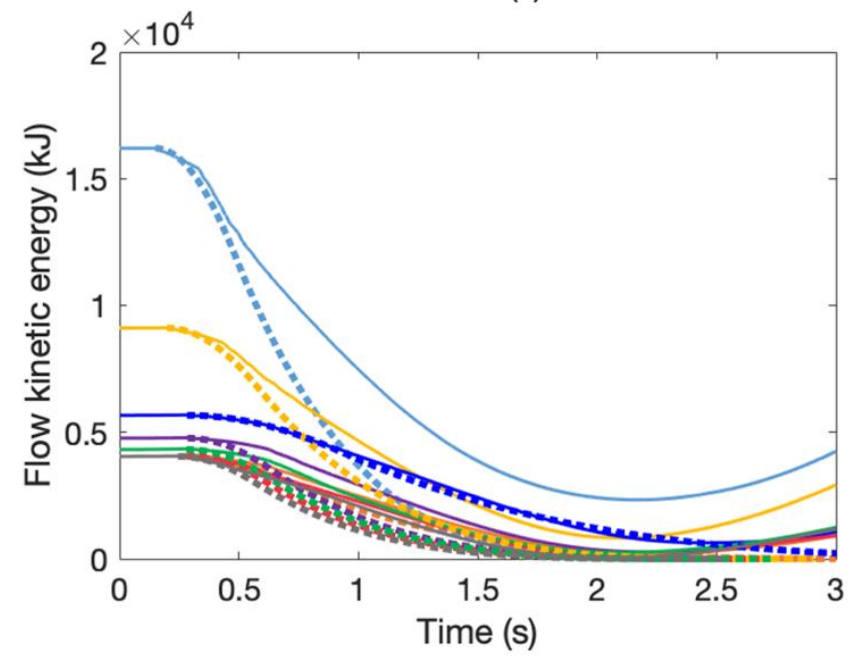

Figure 9. Calibration of the empirical model through the MPM simulations (cases in Tables 1 and 4)

Table 4. Selected parameters for the calibration of the empirical model through MPM simulations

\begin{tabular}{|c|c|c|c|c|c|}
\cline { 2 - 6 } \multicolumn{1}{c|}{} & \multicolumn{4}{c|}{ Flow type landslide } & Barrier \\
\cline { 2 - 6 } & $n(-)$ & $h(m)$ & $V_{1}\left(\mathrm{~m}^{3} / \mathrm{m}\right)$ & $v_{1,0}(\mathrm{~m} / \mathrm{s})$ & $\beta\left(^{\circ}\right)$ \\
\hline Set I & 0.3 & 3 & $45(i=3)$ & 10 & 60 \\
\hline Set II & 0.5 & 3 & $45(i=3)$ & 15 & 60 \\
\hline Set III & 0.5 & 3 & $63(i=5)$ & 10 & 60 \\
\hline Set IV & 0.5 & 3 & $45(i=3)$ & 10 & 80 \\
\hline Set V & 0.5 & 4 & $48(i=1)$ & 10 & 60 \\
\hline
\end{tabular}


446 The impact scenarios used in the above-mentioned analyses are firstly used to compare the 447 output of the proposed empirical method with the numerical results for the most relevant quantities 448 in a LSI analysis (Fig. 10). Based on the above calibration, the values of $F_{\text {peak }}$ and $T_{1}$ computed 449 through the empirical method (Eq. 5 and Eq. 17, respectively) fit very well the MPM numerical results 450 for all the scenarios. On the other hand, as a first validation of the method, it is observed that the 451 impact period $T_{2}$ (computed from Eq. 16) is only slightly overestimated by the empirical method 452 especially for those cases with higher velocities. In these cases, the empirical method is not able to 453 consider the amount of material which overtops the barrier. In fact, as the mass $m_{1}$ decreases, this 454 material no longer contributes to the variation of the linear momentum of the landslide (Eq. 7), 455 therefore a lower value of $T_{2}$ is expected from Eq. Only if the empirical equation is applied to the 456 condition of the indefinite wall (case 3), where the overtopping of the barrier is not allowed, then the 457 empirically-computed time $T_{2}$ perfectly matches the MPM outcome. In this case, even the other 458 calculated quantities correspond to those obtained from MPM since the indefinite wall most resemble 459 the basic assumptions of the empirical model.

460 For the evaluation of the flow kinetic energy at the peak impact force time, i.e. $E_{k, 1}\left(T_{1}\right)$, the empirical 461 formulation provides lower values than MPM for the cases with $v_{1,0}>10 \mathrm{~m} / \mathrm{s}$, while there is an 462 appreciable matching for the other cases. This is mainly caused by the inability of the simplified 463 proposed method to consider the hydro-mechanical coupling and large deformations within the flow, 464 which play a crucial role during the interaction with the obstacle. 
$\Delta$ case 1 * case $2 \circ$ case $3 \circ$ Set I $\square$ Set II $\diamond$ Set III $\times$ Set IV + Set V
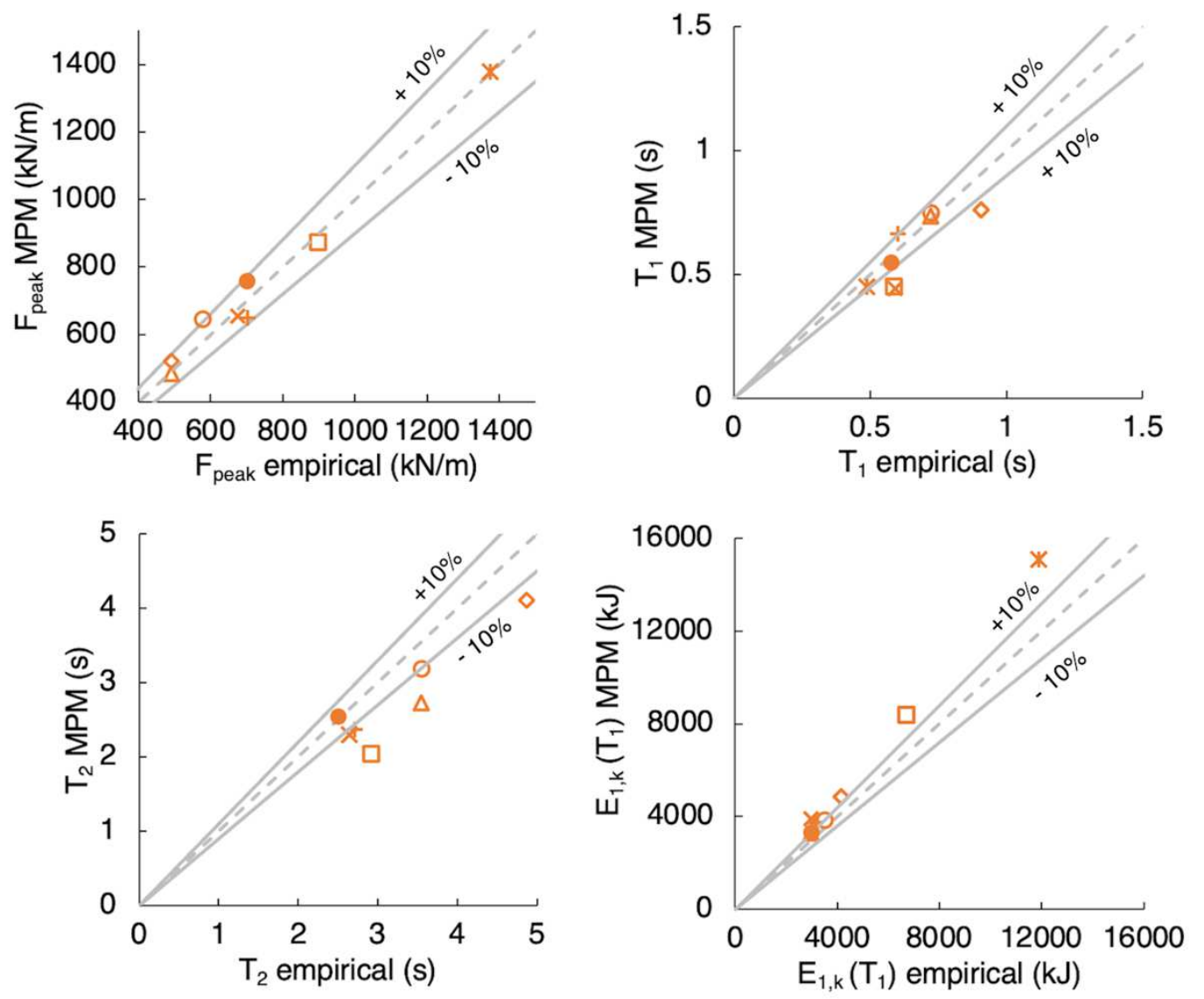

Figure 10. Comparison of MPM and proposed empirical model

The proposed empirical method is more thoroughly validated towards the interpretation of a large dataset of real observations of flow-type landslides, achieved through a permanent monitoring station. The field dataset from Hong et al. (2015) includes thickness, density, channel width, volume of discharge, velocity and impact forces recorded in real time during debris flow events.

The data are relative to 139 historical events that took place between 1961 and 2000 in the Jiangjia Ravine basin, located in the Dongchuan area of Yunnan Province in China (Zhang and Xiong, 1997; Kang et al., 2007; Hong et al. 2015). The bulk density ranges from 1600 to $2300 \mathrm{~kg} / \mathrm{m}^{3}$ with fluid concentration ranging from 0.15 to 0.6 . The dataset is well suited for the validation purpose as wide ranges of the relevant features are considered such as: $v_{1,0}=3-14 \mathrm{~m} / \mathrm{s}, h=0.2-2.7 \mathrm{~m}$, $V_{1}=269-1.75 \cdot 10^{6} \mathrm{~m}^{3}$ and $p_{\text {peak }}=14-435 \mathrm{kPa}$.

The impact pressure is calculated through the calibrated power law (Eq. 19). The results are reported in Fig. 11 and show a very good correspondence with the field data, being the difference much less than $10 \%$ for most of the cases. In particular, the empirical model predicts quite well the peak of impact pressure for low values but showing some dispersion for values higher than $150 \mathrm{kPa}$. The statistical distribution of the error, obtained as the difference between the computed value and 
the measured value, shows that the median value is $7.18 \mathrm{kPa}$ and the $90^{\text {th }}$ percentile value is 36.67 $\mathrm{kPa}$. The application of the numerical MPM model to such a large field data-set is beyond the scope this paper, while it could be a future development.

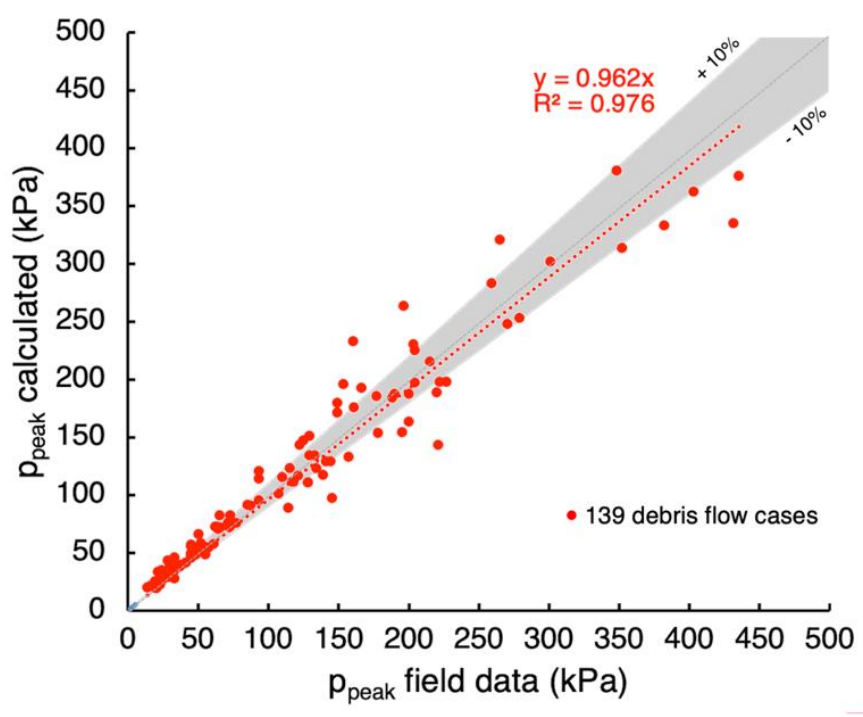

Figure 11. Application of the proposed empirical model to the large field dataset (139 cases) collected by Hong et al. (2015).

\section{Discussion}

A comparison between the presented methods is necessary to assess their strengths and weaknesses for analyzing Landslide-Structure-Interaction.

MPM is an advanced numerical method and has proved to be reliable in predicting the impact force trend over time (Cuomo et al., 2021). Moreover, unlike field evidence or laboratory tests, the numerical results provide additional features, through the computation and time-space tracking of different quantities, such as stress, strain, pore pressure, solid and liquid velocities, which cannot be easily monitored or obtained in the field.

Particularly focusing on LSI, MPM has many advantages. Primarily, it allows considering all such important aspects of the saturated flows, i.e. hydro-mechanical coupling and large deformations during propagation and impact. The accurate knowledge of the impact mechanism and so the evolution of flow depth and velocity is crucial for the design of mitigation countermeasures. For example, the accurate estimate of the length of the vertical jet must prevent that the retaining structure is overtopped by the flow, thus being ineffective. However, MPM suffers from some limitations, such as the high computational cost and until now the difficulty of being available in engineering practice. 
Empirical methods are more immediate and easier to use than MPM, since they provide an estimate of the impact quantities considering only the flow density, thickness and velocity as input and thus they could be preferable in the assessment of the $L S /$ problems for design purposes.

The proposed empirical method is hence compared to some empirical formulations available in the scientific literature (Fig. 12). The chosen empirical formulations are those of Hübl and Holzinger 514 (2003), Armanini et al. (2011), Cui et al. (2015) and Vagnon (2020), all included in the mixed models. already considered in paragraph 4.3. The proposed empirical model reports the highest correspondence among the real data and the computed values, with a contained dispersion of the results. The empirical models of Armanini et al. (2011) and Vagnon (2020) are also acceptable with a low dispersion of the calculated values but with a high overestimate of $61 \%$ and $35 \%$, respectively. The formulations proposed by Hübl and Holzinger (2003) and Cui et al. (2015) are, in contrast, characterized by a quite relevant variability of the achieved results.

Summing up all the outcomes, the MPM-based empirical model predicts very well all such important quantities related to the $L S I$ problem, although with some discrepancy of the results for very high velocities.

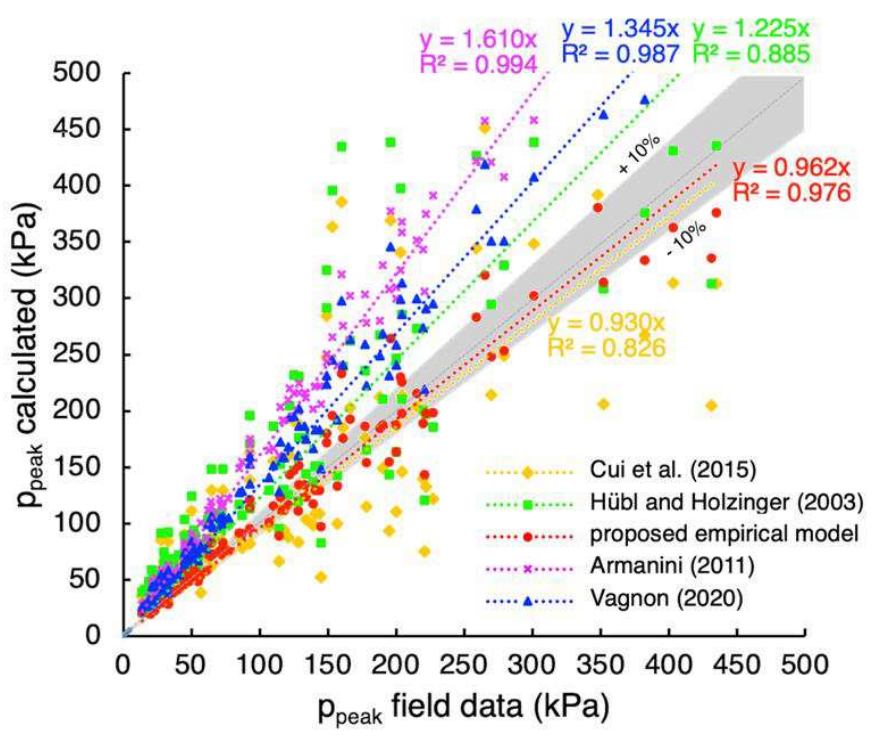

Figure 12. The proposed empirical method compared to some literature empirical methods

\section{Conclusions}

The present paper proposed a conceptual framework and a numerical MPM model to analyse the impact of flow-like landslides against artificial barriers, focusing not only on the evaluation of the peak impact forces but also on the kinematics of the landslide during the whole impact process. 
The conceptual framework for the Landslide-Structure-Interaction (LSI) problem was firstly introduced to better focus the main variables that govern the dynamics of the impact process. This framework has been then implemented inside the proposed methods: numerical (MPM) and empirical.

Specifically, parametric MPM analysis has been conducted to highlight the wide range of impact scenarios that can occur considering all the main features of $L S I$, such as the hydro-mechanical coupling, the soil large deformations and the presence of multi-materials.

Then, a calibration of the new proposed empirical method was performed using the MPM outcomes was conducted. It was possible to derive a new $\alpha-F r$ power law relationship to derive the peak impact pressure. This formulation is different from those in the literature, which are typically calibrated on small-scale laboratory tests, thus giving an excessive overestimation in predicting the impact load that may results in a large increment of costs for structure construction.

Finally, the empirical method was validated referring to a vast dataset of real field evidence collected at Jiangjia Ravine (China). The achieved results are encouraging, showing a high correspondence between the output of the proposed empirical formulation and the measured field data. However, the estimated power law for the empirical model can lead to an underestimation of peak pressures for values larger than $350 \mathrm{kPa}$, so it must be used with caution. Nevertheless, also the available literature methods are applied to the same database, and thus the advantages of the new method are outlined.

In conclusion, the models proposed in this study show a good capability to predict the impact dynamics and kinematics. Further research may be directed to an enhancement of the proposed empirical model considering the amount of material that can overtop the barrier, giving more accurate results for the analysis of the $L S I$ problem.

\section{Acknowledgments}

The research was developed within the framework of Industrial Partnership PhD Course 562 (POR Campania FSE 2014/2020). All the MPM simulations were performed using a version of 563 Anura3D developed by Deltares.

\section{Funding}

The research was supported by a number of Italian Research Projects funded by the Italian Education and Research Ministry such as: Project FARB 2017 "Numerical modelling and inverse analysis for flow-like landslides"; Project FARB 2014 "Large area analysis of triggering and propagation landslide susceptibility for flow-like landslides"; Project FARB 2012 "New Frontiers of advanced numerical simulation of destructive landslides". 


\section{Contributions}

Angela Di Perna is responsible for conceptualization, data collection and numerical modelling. Sabatino Cuomo is responsible for the data collection, numerical modelling and the corresponding passages in the manuscript. Mario Martinelli is responsible for numerical modelling and conceptualization. The authors read and approved the final manuscript.

\section{Competing interests}

The authors declare that we have any competing financial interests.

\section{References}

Al-Kafaji, I. 2013. Formulation of a dynamic material point method (MPM) for geomechanical problems. Ph.D. thesis, University of Stuttgart.

Arattano, M., \& Franzi, L. J. N. H. (2003). On the evaluation of debris flows dynamics by means of mathematical models. Natural Hazards and Earth System Sciences, 3(6), 539-544.

Armanini, A., Larcher, M., and Odorizzi, M. (2011). Dynamic impact of a debris flow front against a vertical wall. In Proceedings of the 5th international conference on debris-flow hazards mitigation: mechanics, prediction and assessment, Padua, Italy (pp. 1041-1049).

Ashwood, W., and Hungr, O. (2016). Estimating total resisting force in flexible barrier impacted by a granular avalanche using physical and numerical modeling. Canadian Geotechnical Journal, 53(10), 1700-1717.

Bugnion, L., McArdell, B. W., Bartelt, P., and Wendeler, C. (2012). Measurements of hillslope debris flow impact pressure on obstacles. Landslides, 9(2), 179-187.

Bui, H. H., \& Fukagawa, R. (2013). An improved SPH method for saturated soils and its application to investigate the mechanisms of embankment failure: Case of hydrostatic pore-water pressure. International Journal for numerical and analytical methods in geomechanics, 37(1), 31-50.

Calvetti, F., Di Prisco, C. G., \& Vairaktaris, E. (2017). DEM assessment of impact forces of dry granular masses on rigid barriers. Acta Geotechnica, 12(1), 129-144.

Canelli, L., Ferrero, A. M., Migliazza, M., and Segalini, A. (2012). Debris flow risk mitigation by the means of rigid and flexible barriers-experimental tests and impact analysis. Natural Hazards and Earth System Sciences, 12(5), 1693-1699.

Ceccato, F., Yerro A., and Martinelli M. (2018). Modelling soil-water interaction with the Material Point Method. Evaluation of single-point and double-point formulations. NUMGE, 25-29 June. Porto, Portugal

Cui, P., Zeng, C., and Lei, Y. (2015). Experimental analysis on the impact force of viscous debris flow. Earth Surface Processes and Landforms, 40(12), 1644-1655. 
Cuomo, S., Prime, N., lannone, A., Dufour, F., Cascini, L., \& Darve, F. (2013). Large deformation FEMLIP drained analysis of a vertical cut. Acta Geotechnica, 8(2), 125-136.

Cuomo, S., Moretti, S., Frigo, L., Aversa, S. (2019). Deformation mechanisms of deformable geosynthetics-reinforced barriers (DGRB) impacted by debris avalanches. Bulletin of Engineering Geology and the Environment, 1-14.

Cuomo, S., Di Perna, A., and Martinelli, M. (2021). MPM hydro-mechanical modelling of flows impacting rigid walls. Canadian Geotechnical Journal.

De Natale, J. S., Iverson, R. M., Major, J. J., LaHusen, R. G., Fiegel, G. L., and Duffy, J. D. (1999). Experimental testing of flexible barriers for containment of debris flows. Reston: US Department of the Interior, US Geological Survey.

Faug, T. 2015. Depth-averaged analytic solutions for free-surface granular flows impacting rigid walls down inclines. Physical Review E, 92(6), 062310.

Fern, J., Rohe, A., Soga, K., and Alonso E. (2019). The material point method for geotechnical engineering: a practical guide. CRC Press.

He, S., Liu, W., \& Li, X. (2016). Prediction of impact force of debris flows based on distribution and size of particles. Environmental Earth Sciences, 75(4), 298.

Hong, Y., Wang, J. P., Li, D. Q., Cao, Z. J., Ng, C. W. W., and Cui, P. (2015). Statistical and probabilistic analyses of impact pressure and discharge of debris flow from 139 events during 1961 and 2000 at Jiangjia Ravine, China. Engineering Geology, 187, 122-134.

Hübl, J., Suda, J., Proske, D., Kaitna, R., and Scheidl, C. (2009). Debris flow impact estimation. In Proceedings of the 11th international symposium on water management and hydraulic engineering, Ohrid, Macedonia (Vol. 1, pp. 1-5).

Hungr, O., Morgan, G. C., and Kellerhals, R. (1984). Quantitative analysis of debris torrent hazards for design of remedial measures. Canadian Geotechnical Journal, 21(4), 663-677.

Idelsohn, S. R., Oñate, E., and Pin, F. D. (2004). The particle finite element method: a powerful tool to solve incompressible flows with free-surfaces and breaking waves. International journal for numerical methods in engineering, 61(7), 964-989.

Iverson, R. M. (1997). The physics of debris flows. Reviews of geophysics, 35(3), 245-296.

Li, X., Zhao, J., \& Soga, K. (2021). A new physically based impact model for debris flow. Géotechnique, 71(8), 674-685.

Jassim, I., Stolle, D., and Vermeer, P. (2013). Two-phase dynamic analysis by material point method. International journal for numerical and analytical methods in geomechanics, 37(15), 2502-2522.

Jeong, S., \& Lee, K. (2019). Analysis of the impact force of debris flows on a check dam by using a coupled Eulerian-Lagrangian (CEL) method. Computers and Geotechnics, 116, 103214.

Kang, Z. C., Cui, P., Wei, F. Q., and He, S. F. (2007). Data collection of observation of debris flows in Jiangjia Ravine, Dongchuan Debris Flow Observation and Research Station (1995-2000). 
Kwan, JSH. (2012). Supplementary technical guidance on design of rigid debris-resisting barriers. GEO Report No. 270, Geotechnical Engineering Office, Civil Engineering and Development Department, Hong Kong SAR Government.

Leonardi, A., Wittel, F. K., Mendoza, M., Vetter, R., \& Herrmann, H. J. (2016). Particle-fluid-structure interaction for debris flow impact on flexible barriers. Computer-Aided Civil and Infrastructure Engineering, 31(5), 323-333.

Luo, H., Baum, J. D., and Löhner, R. 2008. A discontinuous Galerkin method based on a Taylor basis for the compressible flows on arbitrary grids. Journal of Computational Physics, 227(20), 8875-8893.

Mast, C. M., Mackenzie-Helnwein, P., Arduino, P., Miller, G.R. and Shin W. (2012). Mitigating kinematic locking in the material point method. Journal of Computational Physics, 231(16), 53515373.

Mieremet, M. M. J., Stolle, D. F., Ceccato, F., and Vuik, C. 2016. Numerical stability for modelling of dynamic two-phase interaction. International Journal for Numerical and Analytical Methods in Geomechanics, 40(9), 1284-1294.

Ng, C. W. W., Majeed, U., Choi, C. E., and De Silva, W. A. R. K. (2021). New impact equation using barrier Froude number for the design of dual rigid barriers against debris flows. Landslides, 1-13.

Proske, D., Suda, J., and Hübl, J. (2011). Debris flow impact estimation for breakers. Georisk, 5(2), 143-155.

Qiu, G., Henke, S., \& Grabe, J. (2011). Application of a Coupled Eulerian-Lagrangian approach on geomechanical problems involving large deformations. Computers and Geotechnics, 38(1), 3039.

Scheidl, C., Chiari, M., Kaitna, R., Müllegger, M., Krawtschuk, A., Zimmermann, T., and Proske, D. (2013). Analysing debris-flow impact models, based on a small scale modelling approach. Surveys in Geophysics, 34(1), 121-140.

Scotton, P., and Deganutti, A.M. (1997). Phreatic Line and Dynamic Impact in Laboratory Debris Flow Experiments.

Shen, W., Zhao, T., Zhao, J., Dai, F., \& Zhou, G. G. (2018). Quantifying the impact of dry debris flow against a rigid barrier by DEM analyses. Engineering Geology, 241, 86-96.

Song, D., Ng, C. W. W., Choi, C. E., Zhou, G. G., Kwan, J. S., and Koo, R. C. H. 2017. Influence of debris flow solid fraction on rigid barrier impact. Canadian geotechnical journal, 54(10), 14211434.

Song, D., Zhou, G. G., Chen, X. Q., Li, J., Wang, A., Peng, P., \& Xue, K. X. (2021). General equations for landslide-debris impact and their application to debris-flow flexible barrier. Engineering Geology, 288, 106154.

Thouret, J. C., Antoine, S., Magill, C., and Ollier, C. (2020). Lahars and debris flows: Characteristics and impacts. Earth-Science Reviews, 201, 103003. 
Vagnon, F. (2020). Design of active debris flow mitigation measures: A comprehensive analysis of existing impact models. Landslides, 17(2), 313-333.

Vagnon, F., and Segalini, A. (2016). Debris flow impact estimation on a rigid barrier. Natural Hazards and Earth System Sciences, 16(7), 1691-1697.

Zhang, J., and Xiong, G. (1997). Data collection of kinematic observation of debris flows in Jiangjia Ravine, Dongchuan, Yunnan (1987-1994).

Zhou, G. G. D., Song, D., Choi, C. E., Pasuto, A., Sun, Q. C., and Dai, D. F. (2018). Surge impact behavior of granular flows: effects of water content. Landslides, 15(4), 695-709.

\section{Appendix 1. Material Point Method model equations}

The Material Point Method (MPM) is an enhancement of the Finite Element Method (FEM), and it is very well suited for large deformation problems. The continuum body consists of several Lagrangian points (named material points, MPs), which carry all the physical properties of the continuum such as stress, strain, density, momentum, material parameters and other state parameters. The MPs move across a background mesh, which covers the domain where the material is expected to move, and it is used to solve the governing equations without storing any permanent information.

A saturated porous medium is schematized as a solid phase which represents the solid skeleton, whereas the liquid phase fills the voids among the grains. Each MP represents a volume of the mixture $V$, given by the sum of the solid $\mathrm{V}_{S}$ and liquid $\mathrm{V}_{L}$ phases volumes. The behaviour of a saturated porous medium is here described using only one set of MPs, in which the information about both the solid and liquid constituents is stored. The interaction between phases (solid and liquid in a saturated soil) can be tacked through the two-phase single-point formulation (Jassim et al., 2013; Ceccato et al., 2018), where the liquid and the solid acceleration fields ( $\mathbf{a}_{S}-\mathbf{a}_{L}$ formulation) are the primary unknowns (Fern et al., 2019).

The velocity field of solid and liquid phases are both used, but the material points move throughout the mesh with the kinematics of the solid skeleton. The equations to be solved concern the balance of dynamic momentum of solid and liquid phases, the mass balances, and the constitutive relationships of solid and liquid phases. The accelerations of the two phases are the primary unknowns: the solid acceleration $\mathbf{a}_{S}$, which is calculated from the dynamic momentum balance of the solid phase (Eq. A1), and the liquid acceleration $\mathbf{a}_{L}$, which is obtained by solving the dynamic momentum balance of the liquid phase (Eq. A2). The interaction force between solid and liquid phases is governed by Darcy's law (Eq. A3). Numerically, these equations are solved at grid nodes considering the Galerkin method (Luo et al., 2008) with standard nodal shape functions and their solutions are used to update the MPs velocities and momentum of each phase. The strain rate $\dot{\varepsilon}$ of MPs is computed from the nodal velocities obtained from the nodal momentum. 
$\mathbf{f}_{d}=\frac{n \mu_{L}}{k}\left(\mathbf{v}_{L}-\mathbf{v}_{S}\right)$

The resolution of solid and liquid constitutive laws (Eqs. A4-A5) allows calculating the increment of effective stress $d \boldsymbol{\sigma}^{\prime}$ and excess pore pressure $d p_{L}$, respectively. The mass balance equation of the solid skeleton is then used to update the porosity of each MP (Eq. A6), while the total mass balance serves to compute the volumetric strain rate of the liquid phase (Eq. A7) since fluxes due to

$\mathrm{d} \boldsymbol{\sigma}^{\prime}=\mathbf{D} \cdot \mathrm{d} \boldsymbol{\varepsilon}$

$\mathrm{d} p_{L}=\mathbf{K}_{L} \cdot \mathrm{d} \varepsilon_{\text {vol }}$

$\frac{D n}{D t}=n_{S} \nabla \cdot \mathbf{v}_{S}=\mathbf{0}$

$\frac{D \varepsilon_{v o l}}{D t}=\frac{n_{S}}{n} \nabla \cdot \mathbf{v}_{S}+\nabla \cdot \mathbf{v}_{L}$

In the two-phase single-point formulation the liquid mass, and consequently the mass of the mixture, is not constant in each material point but can vary depending on porosity changes. Fluxes due to spatial variations of liquid mass are neglected and Darcy's law is used to model solid-liquid interaction forces. For this reason, this formulation is generally used in problems with small gradients of porosity, and laminar and stationary flow in slow velocity regime. However, this formulation proves to be suitable for studying flow-structured-interaction (Cuomo et al., 2021). The water is assumed linearly compressible via the bulk modulus of the fluid $\mathbf{K}_{L}$ and shear stresses in the liquid phase are neglected.

The current MPM code uses 3-node elements which suffer kinematic locking, which consists in the build-up of fictitious stiffness due to the inability to reproduce the correct deformation field (Mast et al., 2012). A technique used to mitigate volumetric locking is the strain smoothening technique, which consists of smoothing the volumetric strains over neighbouring cells. The reader can refer to Al-Kafaji (2013) for a detailed description.

Regarding the critical time step, the influence of permeability and liquid bulk modulus must be considered as well (Mieremet et al., 2016). In particular, the time step required for numerical stability is smaller in soil with lower permeability (Eq. A8). 
$754 \Delta t_{c r}=\min \left(\frac{d}{\sqrt{\left(E+\mathbf{K}_{L} / n\right) / \rho_{m}}} ; \frac{2\left(\rho_{m}+(1 / n-2) \rho_{L}\right) k_{s a t}}{\rho_{L} \boldsymbol{g}}\right)$

The sliding modelling of the flowing mass on the rigid material is handled by a frictional Mohr758 Coulomb strength criterion. The contact formulation was used to ensure that no interpenetration 759 occurs, and the tangential forces are compatible with the shear strength along the contact. The 760 reaction force acting on the structure at node $j$ was calculated as in Eq. A9.

The terms $\Delta a_{S, \text { contact }}$ and $\Delta a_{L, \text { contact }}$ are the change in acceleration induced by the contact 765 formulation, for both solid and liquid phase, and $m_{i, S}$ and $m_{i, L}$ are the corresponding nodal masses. 766 The total reaction force is the integral of the nodal reaction forces along the barrier. 